\title{
The Impact of Assistive Software Application to Facilitate People with Dementia through Participatory Research
}

\author{
Ikram Asghar ${ }^{1}$, Shuang $\mathrm{Cang}^{2}$ and Hongnian $\mathrm{Yu}^{3,4^{*}}$ \\ ${ }^{1}$ Faculty of Faculty of Computing, Engineering and Science, University of South Wales, Pontypridd, \\ United Kingdom, ikram.asghar@southwales.ac.uk \\ ${ }^{2}$ Department of Computing and Technology, School of Science and Technology, Nottingham Trent \\ University, United Kingdom, shuang.cang@ntu.ac.uk \\ ${ }^{3 *}$ Corresponding author: Hongnian $\mathrm{Yu}$, Department of Automation, School of Electrical Engineering, \\ Zhengzhou University, China \\ ${ }^{4}$ School of Engineering and the Built Environment, Eedinburgh Napier University, United Kingdom, \\ h.yu@napier.ac.uk
}

\begin{abstract}
Due to the ever-increasing number of people with dementia (PWD), the researchers are challenged with finding innovative ways for their wellbeing. This study explores the development and usability of a software application named the assistive brotherhood community (ABC) application as a potential alternative to help PWD. The ABC application is based on the actual requirements elicited from the PWD, and it supports multiple functionalities. The usability is tested through case studies involving eight PWD and 40 volunteers. The ABC application helped the PWD in getting their daily needs while staying in their homes. It further aided them in specific reminders, evoking memories, independent travel and updating events around them. Additionally, the enhanced interaction between the PWD and their neighbours reduced their social isolation. The results support the idea to create dementia-friendly communities at street level by combining the PWD, technology and people support. Such communities can potentially offer cost-effective and friendly environments for the PWD.
\end{abstract}

Keywords: Dementia; assistive software application; socialization; travel; daily needs 


\section{Introduction}

Ageing becomes a recognized phenomenon around the world. Some regions have more people over the age of 60 as compared to under age of 14 children. This trend is expected to prevail around the globe (Chamie, 2004). The United Nations survey shows that there are 11.7\% (841 million people) over the age of 60 and this figure is expected to rise 21.1\% (2 billion people) by 2050 (Au, Lai, \& Ng, 2015). The ageing population is contributing considerably to the number of people with dementia (PWD) worldwide.

\subsection{Dementia Statistics and its Impacts}

Dementia has over 100 symptoms, which make it a complex disease. It is a comprehensive class of "brain diseases that include any disease that causes loss of cognitive ability (ability to think and reason clearly) that is severe enough to affect a person's daily functioning” (Span, Hettinga, Vernooij-Dassen, Eefsting, \& Smits, 2013). The recent estimates suggest that the global population of the PWD has reached 50 million (International, 2017). It has a substantial economic impact as the annual dementia care costs in the form of care homes, caregivers, doctors and medical facilities are worth $\$ 818$ billion (Pratchett, 2015). These costs are much higher than the prices of any other disease (Cire, 2015). On the other hand, the ratio of PWD and caregivers is going to reduce from (69:1) in 2000 to (21:1) in 2050 due to an expected drop in the workforce. Over 70\% of PWD will live within communities and require support from the community (Wancata, Musalek, Alexandrowicz, \& Krautgartner, 2003). Resultantly, worldwide research has increased on improving the wellbeing of the PWD using technologies. However, almost 94\% of these studies are produced in the USA, UK, Canada, Sweden, Italy, Germany, Netherlands, France, Australia and Spain, that present western point of view related to technology use for the PWD (Asghar, Cang, \& Yu, 2017a). There is a lack of such research in other regions, including South Asia.

\subsection{Dementia Research in South Asia and Pakistan}

We took this as a challenge and investigated the state of PWD research in the South Asia region. The importance of such a study becomes even more significant as South Asia accounts for $25 \%$ of the Worlds' population (Rasul, 2014). The South Asian region is home to 4.5 million PWD (Prince et al., 2013). Considering this, the South Asian researchers have conducted a few studies for their wellbeing (Ali \& Bokharey, 2015). However, these studies focus on improving their wellbeing through the caregivers and family members. Globally, there are few studies on the usability of the technological solutions for the PWD (summarized in the related work section). However, to the best of the authors' 
knowledge, there is no technology usability evaluation study conducted in the South Asian region with a focus on the PWD (Asghar et al., 2017a).

This study is conducted in Pakistan, which has more than 150,000 PWD living in different parts of the country. The dementia population is increasing at a rate of $1.9 \%$ every year, which can create challenges for an already weak economy of the country (Ahmad et al., 2013). Moreover, there is only one care home in the country for the PWD (the daycare centre at Lahore, where the PWD can only stay during daytime). In addition to this, a recent study has suggested developing solutions to be used at home, as Pakistani families prefer homecare based intervention for the PWD due to their cultural beliefs (Zaidi et al., 2019). The use of assistive technology is considered as an alternative to help the PWD at their own homes. Therefore, this study is timely to involve them in such a research in Pakistan.

\subsection{Study Objectives}

This study describes the development and usability evaluation of software solutions designed for the PWD named as the Assistive Brotherhood Community (ABC) application. The ABC application is designed based on the actual requirements of 347 PWD gathered through prior surveys (Asghar, Cang, \& Yu, 2018a) and (Asghar, Cang, \& Yu, 2018b).

The primary purpose of this study is to analyse the impacts of the ABC application through case studies and interviews. The user-centric approach has helped to achieve the following research objectives:

Objective 1: To develop a software application based on PWD requirements.

Objective 2: To conduct experiments with the PWD.

Objective 3: To investigate the support of the application for the PWD.

\section{Related Work}

This section covers details about the recent advancements in technological solutions of usability evaluation studies for the PWD.

\subsection{Assistive Technologies for the People with Dementia}

The past ten years have witnessed large scale development of technological solutions as many studies showed that such solutions could be an alternative to help the PWD (Tchalla et al., 2012) (Fardoun, Mashat, \& Ramirez Castillo, 2015).

The PWD usually face memory-related cognitive challenges; therefore, reminders and prompts were considered useful for them. An electronic organizer APL@LZ was developed to remind the PWD about 
their medication times and the trials proved helpful for the PWD in taking timely medication (Imbeault et al., 2014). Cyberminder was used to generate smart alerts based on the activities of the PWD, their location and time. The smart reminders helped the PWD in completing predetermined tasks (Dey \& Abowd, 2000). The systems developed by Hoey et al. and Aloulou et al. monitored the activities of the PWD at their homes through video cameras. The system assisted the PWD to carry out their tasks step by step in the correct sequence (Hoey et al., 2010) (Aloulou et al., 2013).

Communication aid solutions have also been used for helping the PWD. The use of a mobile phone can be difficult for some of the PWD; therefore, Boman et al. developed a user-friendly videophone for them. The trials showed that videophones performed better for the PWD as compared to traditional mobile phones (Boman, Lundberg, Starkhammar, \& Nygård, 2014). Similarly, a mobile phone-based video streaming system (MPVS) has been successfully used to send video messages between the PWD and their caregivers (Donnelly et al., 2010b).

Some researchers have even tried robots to help the PWD in their daily activities. The ROBODOM was once used to interact with the PWD through verbal and non-verbal communication (Wu et al., 2013). However, the Social Assistive Robot (SAR) has taken over, and it was considered as a useful therapeutic solution for the PWD that could help them to regain their confidences (Mordoch, Osterreicher, Guse, Roger, \& Thompson, 2013). Interestingly another study showed that robots could have a better impact on the PWD when healthcare information is delivered through them as compared to information delivery through humans (Mann, MacDonald, Kuo, Li, \& Broadbent, 2015).

The advances in this digital age have increased the use of the internet by old people, which can contribute towards the utilization of the software solutions for their betterment. The software solutions have been popularly used in education, medicine, aerospace, flight operations, sports, etc. Similarly, such solutions have the potential to support PWD. Our previous work based on a comprehensive investigation of 51 software solutions, identified eight potential areas of support (cognitive help, reminders, health monitoring, socialization, leisure, travel, dementia detection and dementia prevention) for the PWD (Asghar, Cang, \& Yu, 2016). Many researchers believed that the advantages of using a software solution made it a potential cost-effective solution for the PWD that the world was looking for (Sawyer, Sutcliffe, Rayson, \& Bull, 2015) (Asghar, Cang, \& Yu, 2017b). However, this requires further investigation to support such a hypothesis through usability studies. 


\subsection{Technology Abandonment Challenges}

The examples in section 2.1 indicate that there is continuous work going on in the production of technological solutions for the PWD. However, statistics showed that there was a high rate of technology abandonment on the part of the PWD (Carrillo, Dishman, \& Plowman, 2009). This high rate was caused by various reasons including; the technology target single need of the PWD instead of multiple needs, developed without user involvement, uniqueness of dementia needs were not considered (Chaurasia et al., 2016). As a potential solution to AT abandonment, the literature recommended to conduct empirical studies to evaluate the usability and impacts of technology on the lives of the users (Imbeault et al., 2014; Span et al., 2013; Van Hoof, Kort, Duijnstee, Rutten, \& Hensen, 2010).

There are limited empirical studies available in the existing literature. In an empirical research, the opinion of the 22 PWD relatives investigated technology support through the questionnaires. The relatives showed a positive view of the technology used for the wellbeing of the PWD (Engström, Lindqvist, Ljunggren, \& Carlsson, 2006). Satisfaction of 33 staff members with the technology used for the PWD was tested through the questionnaires. The data was collected before and six months after the implementation of technology support (activity monitoring, alarms and fall detectors) at the nursing home. The use of technology significantly improved the job satisfaction of the staff members with their work (Engström, Ljunggren, Lindqvist, \& Carlsson, 2005). Similarly 14 staff members' perception of technology (communication technology, fall detector, alarms and computers) use for the PWD was tested through the interviews. At the start, staff members had diverse perceptions, but after technology implementation, most impressions were on the positive side (Engström, Lindqvist, Ljunggren, \& Carlsson, 2009).

The use of an automated prompt system was analysed by involving eight PWD in trials. The PWD were able to complete more steps with less caregiver involvement through the help of a prompt system (Labelle \& Mihailidis, 2006). Another study investigated the use of a prompter in handwashing activity by involving six PWD. The PWD completed more steps independently, and the number of interactions with the caregivers also reduced (Mihailidis, Boger, Craig, \& Hoey, 2008). The wondering problem was investigated by testing the Global Positioning System (GPS) device with the PWD and asking their future needs through a case study. Although the participants appreciated the use of GPS but showed concerns related to the shape and volume of the device (Faucounau et al., 2009).

The most comprehensive work in this field comes from the Australian researchers who used a systematic review to identify empirical studies on technology use for the PWD (Fleming \& Sum, 2014). They 
concluded that there was still a high rate of non-acceptance of technology, as most of these technologies did not contribute to the needs of the PWD. They further emphasized that it is essential to directly involve the PWD in such studies to analyse the impact of technology on their lives (Fleming \& Sum, 2014).

The research gaps identified through the related work, such as lack of software solutions, user-centric approach and usability evaluation studies involving the PWD, motivated us to conduct this study for achieving research objectives discussed in the previous section.

\section{Methods}

A qualitative, user participatory research design was followed throughout this study based on the recommendations of (Conway, Campbell, Forbes, Cunningham, \& Wake, 2016; Schikhof, Mulder, \& Choenni, 2010). This process included multiple-subjects case studies and semi-structured interviews at different sites. The case studies followed three phases: (i)- trained the PWD to use the application, (ii)the PWD used the app for two days to perform different tasks and (iii)- interviewed PWD for analysing the usability of the application.

\subsection{Participants and Volunteers Selection}

As already introduced, this study was conducted in Pakistan, where the dementia population is continuously rising, and the country lacks in care homes facilities. In Pakistan, there were no research efforts on the use of technology support for the PWD until we started our research in 2015. We conducted two studies involving 327 PWD through questionnaires (Asghar et al., 2018a) and 20 PWD through the interview-based survey (Asghar et al., 2018b). These studies helped researchers to understand the strengths and weaknesses of the PWD in Pakistan who can use technology support. These studies further helped to elicit the requirements of the PWD related to the technological solution they want to use.

For this study, the researchers contacted medical professionals from Pakistan as they had prior links with them. Based on their recommendations, the researchers contacted 12 PWD and many volunteers participating in the case studies. Nine PWD expressed their willingness for participation, but one of them left out due to illness. The remaining 8 PWD and 40 volunteers belonging to five different cities in Pakistan participated in the case studies. The participants included in the survey were shortlisted based on the following criteria:

- The participant gave the written consent to participate in the study

- The participant diagnosed with a mild dementia 
- The participant had moderate cognitive impairment based on the Mini-Mental Scale Examination (MMSE) with scores from 20 to 25.

- The participant had prior knowledge and experience of using software technologies

- The participant understood instructions

The volunteers' selection also followed a systematic process, including:

- The volunteer gave the written consent to participate in the study

- The volunteer personally knew the PWD

- The volunteer lived within the same street as per the PWD

- The volunteer was good at using software technologies

- The volunteer had access to car or bike and willing to purchase goods on behalf of the PWD

For the safety of both the PWD and the volunteers, their aggression and criminal history were discussed with the medical professionals and local union councils. All participants were found positive fit for the case studies.

\subsection{Test Environment}

The study was executed in the central and northern parts of Pakistan, which holds almost $60 \%$ of the country's population. Each test environment included the living place of the PWD and five volunteers from the same street. The specially designed $\mathrm{ABC}$ application was used as a communication medium between the PWD and the volunteers. The ABC application was installed on Tablets for the PWD and the smartphones of each volunteer. The Tablet was hanged on the wall so that the PWD could access it quickly, and it was turned on throughout the case study period. Each case study's activities continued for both days from 9 am to $8 \mathrm{pm}$. The activities of the PWD and volunteers were recorded through electronic $\log$ files. The researcher also lived in the same home to observe and take notes of different actions performed by the PWD.

\subsection{Evaluation Process}

At the beginning of each case study, the PWD and volunteers were explained about their roles. The researcher gave them one-hour training through PowerPoint slides and explained the functionalities of the ABC application. As all selected PWD were familiar with the use of technology, they were able to operate this application through one-hour training, except for one participant who required training three times. A written scenario was developed, which described the use of $\mathrm{ABC}$ application functions in real life and how it can support the PWD to perform different activities. After that, the researcher helped to 
install the $\mathrm{ABC}$ application. Then, they were asked to use the $\mathrm{ABC}$ application in their daily activities. Lastly, the researcher interviewed them to explore their opinions about the usability of the $\mathrm{ABC}$ application.

\subsection{Interviews and Data Analysis}

After each case study, semi-structured interviews were conducted with the PWD. In semi-structured interviews "the interviewer sets up a general structure by deciding in advance the ground to be covered and the main questions to be asked" (Drever, 1995). This method offers interviewers and interviewees a chance to explore the issues in a structured way. The guidelines for designing a semi-structured interview template followed from (Jones, 2004). The structure of the questions kept simple based on the recommendations by (Beuscher \& Grando, 2009). The number of items also kept limited, as it is difficult for the PWD to concentrate for an extended period. The complete process of interview template design and validation was described in (Asghar et al., 2018b).

Usually, for the qualitative studies involving interviews, the thematic mapping analysis is popularly used as it helps to identify, analyse and report patterns within data. As per the Braun and Clarke guidelines, a multi-step thematic mapping analysis process was applied (Braun \& Clarke, 2006).

- Keynotes were taken by listening to interview recordings

- Used NVivo to generate initial codes

- Used mind maps to sort different codes into potential themes

- Refinement of themes

- Official theme names replaced working titles of themes

- Reporting themes with sufficient evidence from the interviews

The thematic analysis resulted in six possible themes related to the usability of the ABC application. The details are discussed in the results and the analysis section.

\subsection{Ethical Considerations}

The ethical approval for the study was taken from the Bournemouth University ethics committee. The interviewer sought willingness of the individuals and their family members as recommended by (Ireland, 2015). Each interview lasted for 30 to 40 minutes. The interview recordings were done with the prior permission of each participant. 


\section{Assistive Brotherhood Community Idea, Development and Evaluation}

This section describes the basic idea for the Assistive Brotherhood Community (ABC), the development of $\mathrm{ABC}$ application (features) and its evaluation through case studies.

\subsection{ABC Idea}

The idea behind the ABC development was to support the PWD through the help of people living within their communities. The concept is explained with the help of a scenario shown in figure 1, where people within the neighbourhood of the PWD can help them in fulfilling their daily needs. For example, an old person with dementia "Mr Ali" lives alone at his home, and he is in a fragile condition. He cannot go to the market to purchase goods and needs a packet of bread. He just opens the ABC application, goes to the daily household section and presses the picture of the 'BREAD'. A message "Mr Ali needs a packet of bread" will spread across the ABC. The volunteers' responses can be; Mr Lee "I am studying", Ms Ana "I am about to drive my car" and Mr Dev "I am bringing the packet of bread in 5 minutes". All these people can see each other's communication as well. In this way, people within the community can help each other without involving any caregiving company or service provider. Furthermore, the response within the community will be quick and friendly. A conceptual idea of the ABC is shown in figure 1.
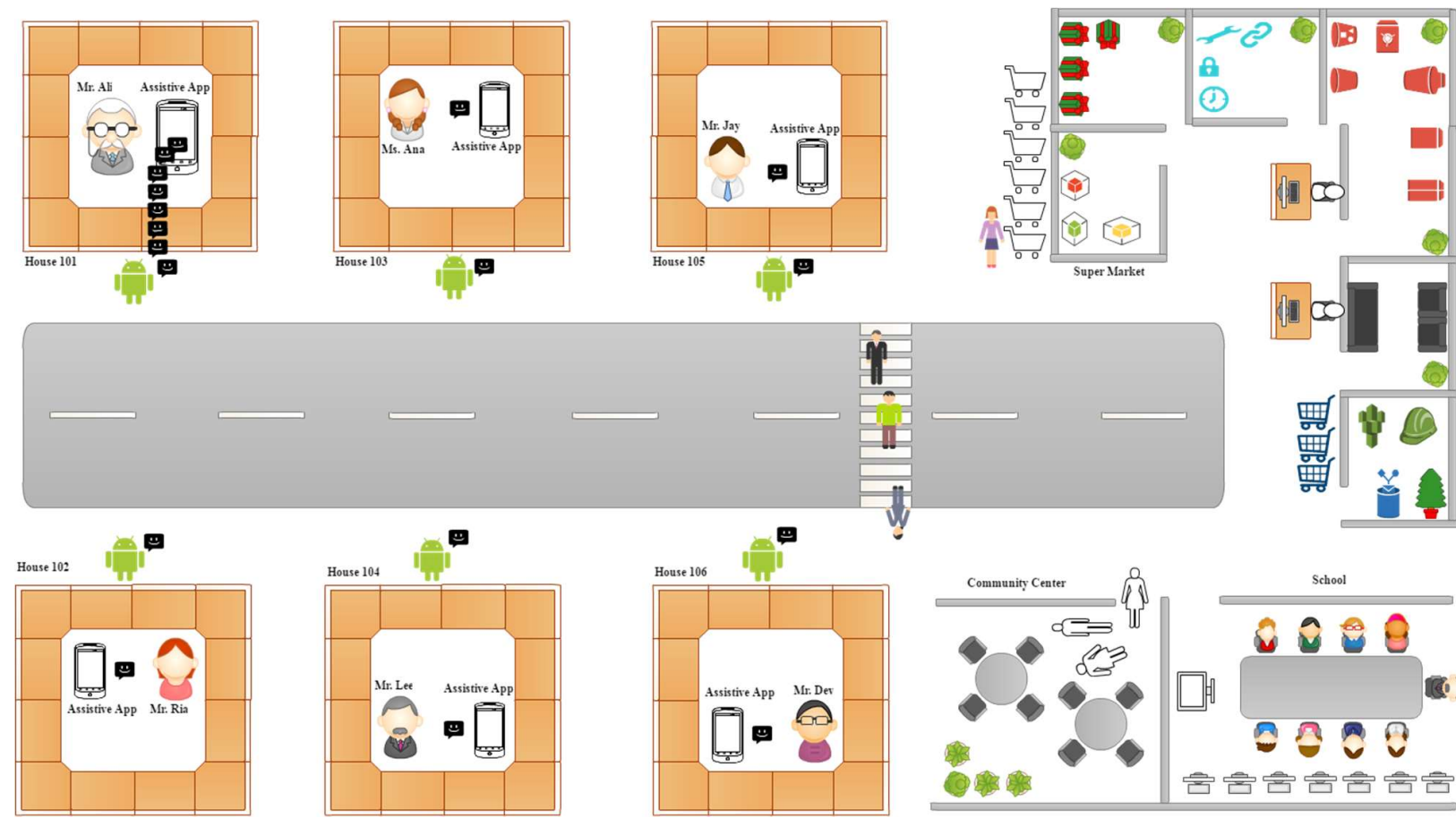

Figure 1. The proposed case study scenario 


\subsection{Features of ABC Applications}

The ABC application focused on the specific requirements of the PWD, explicitly collected for this study through qualitative and quantitative surveys from 347 PWD (Asghar et al., 2018a) (Asghar et al., 2018b). The main requirements gathered from the PWD were categorized into six major groups named as (daily needs at a click, one-touch calls and messaging, reminders, painting memories, news/weather updates and travel tutor). The idea behind the development of the $\mathrm{ABC}$ application was to promote single touch assistance for the PWD using latest android features.

\subsubsection{The Main Interface of the ABC Application}

The interface for any software application is an essential part as it provides the interaction between the system and users. Figure 2(a) shows the primary interface for the ABC application, with tabs for six main functionalities offered by it. A user can use either of these functionalities by just a single click that will take him to the respective functions of that category. The left bottom corner displays the conversational logs of the users.

\subsubsection{Daily Needs at a Click}

Due to ageing, the PWD often have physical challenges in mobility and going out for shopping independently. The ABC application was designed to help the PWD in getting basic daily needs while staying at their own homes. By entering in the first functional category, the user can see the list of different daily household items. The daily household items shown in figure 2(b) include; milk, bread, fruits, vegetables, water, chicken, eggs and rice. The user needing any of these items will just click on the relevant icon. This click will generate a message like 'Mr Ali needs a bottle of milk', which will be sent to all volunteers who have installed the same application on their devices. They can reply and can see each other's communication.

\subsubsection{Calls and Messaging}

The One-touch calls and messaging function shown in figure 2(c) offers two supports, i.e. calls and messaging facilities at a click. Due to cognitive challenges, it is hard for the PWD to remember the phone numbers and names of their loved ones. This function facilitates to save pictures, instead of phone numbers and names. The user does not need to worry about remembering any information and can contact their loved ones on just a click, which automatically dial a call to the desired person. 


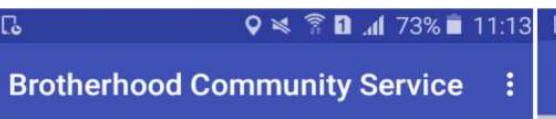

Basic Needs

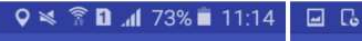

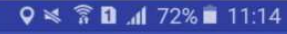

Needs
Click to view Needs
Calls \& Messages
Click to view Calls \& Messages
Reminder
Click to view Reminder
Click to view Paint Your Memories

Calls and Messaging

Cill Taria

a Iran

00047459827349

69 Saleem

Messages

ie. irfan: Ok I am bringing
$23, \mathrm{Mar} 2017$ 10:05 PM

๑. irfan: Ok I am bringing

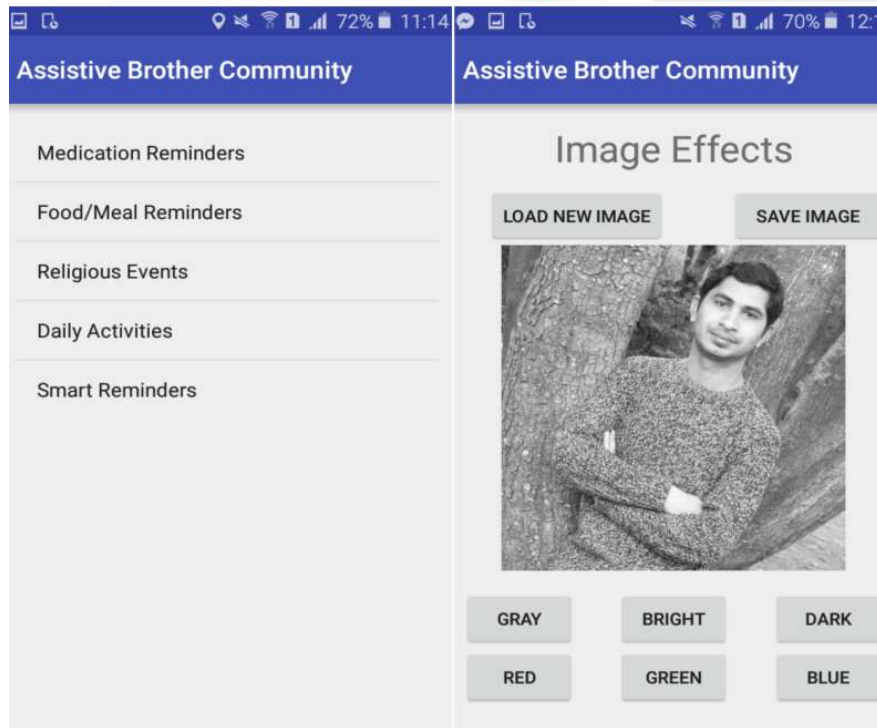

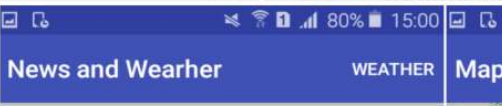

(c)

(d)

(e)

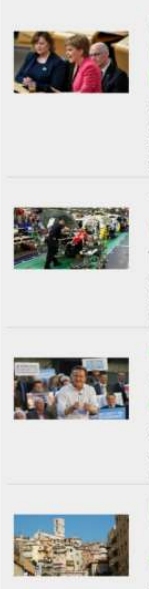

Scottish independence:

be rejected' UK government to reject Nicola
Sturgeon's call for second Scottis
independence referendum by

Figure 2. The functions and working of the assistive software application 


\subsubsection{Reminders}

Due to the continuous decline in memory, the PWD can forget to do their daily activities on time. The reminder functionality shown in figure 2(d) can help them through friendly prompts. The reminders functions included in this application are medication reminders (for taking medicine with details of the dosage), food/meal reminders (for taking food on pre-specified times), religious events (prayer times, church visits, Christmas, etc.), daily activities (specific activity set for that day) and smart reminders (warnings related to weather like rain, snow, wind, etc.).

\subsubsection{Paint Your Memories}

The progression of dementia makes it difficult for the PWD to regenerate their memories from their past. Previous research shows that refreshing the memories of the PWD can have a positive and pleasant effect on them. It can help them boosting and increasing their confidence. The paint your memories function shown in figure 2(e) will help the PWD to load their black and white pictures into the ABC application, and they can change the colour combination of those pictures.

\subsubsection{News and Weather Updates}

The PWD living either at their own homes or care homes are usually not well connected to the rest of society. Therefore, they are not up to date of what is happening around them. The news function shown in figure 2(f) provides them updates related to recent news around the world. The weather function generates recent updates related to the behaviour of weather on an hourly basis.

\subsubsection{Travel Tutor}

Independent travelling is one of the critical challenges associated with dementia. Due to cognitive issues, the PWD is usually unable to travel from one place to another independently and safely. They can forget their way back home as well. The travel tutor function helps the user to go outside and walk around the neighbourhood alone. Whenever the user goes more than 200 meters away from their home location, an automatic alarm is generated warning and asking them to go back home. The travel tutor shown in figure $2(\mathrm{~g})$ will guide the user their way back home as well.

\subsection{Case Study Activities}

The case studies are performed to analyse the performance of $\mathrm{ABC}$ application features in helping the PWD. The activities performed during case studies are summarized in table 1. 
Table 1. Activities Tested During Case Studies

\begin{tabular}{|c|c|c|}
\hline Category & Activity Name & Number of Repetitions \\
\hline \multirow[t]{8}{*}{ Daily Needs } & Request to bring milk & \multirow[t]{8}{*}{ At least three items for each PWD each day } \\
\hline & Request to bring bread & \\
\hline & Request to bring fruits & \\
\hline & Request to bring vegetables & \\
\hline & Request to bring water & \\
\hline & Request to bring chicken & \\
\hline & Request to bring eggs & \\
\hline & Request to bring rice & \\
\hline Calls & Calling a family member or friend & At least two calls for each PWD each day \\
\hline \multirow[t]{4}{*}{ Reminders } & Medication Reminders & Morning, afternoon, night medication reminders for each day \\
\hline & Food/Meal Reminders & Breakfast, lunch, dinner reminders for each day \\
\hline & Religious Events & Five-time prayers reminders for each day \\
\hline & Daily Activities & $\begin{array}{l}\text { At least two activity reminders each day (e.g. to watch TV or go out for } \\
\text { a walk, etc.) }\end{array}$ \\
\hline \multirow[t]{3}{*}{ Painting Memories } & Upload black and white pictures & \multirow[t]{3}{*}{ Use at least two pictures to upload, colour and save each day } \\
\hline & Color the pictures & \\
\hline & Save the coloured pictures & \\
\hline \multirow[t]{2}{*}{ News and Weather } & Read news updates & \multirow[t]{2}{*}{ Use both functions at least once for each day } \\
\hline & See weather updates & \\
\hline \multirow[t]{2}{*}{ Travel Tutor } & Travel outside the home & \multirow[t]{2}{*}{ Travel outside the home for more than 200 meters each day } \\
\hline & Return home & \\
\hline
\end{tabular}

The following scenarios are followed to record the activities and their outcome during the case studies:

- The activity log recorded the requests, responses and time spent on each activity.

- The researcher took notes of the number of reminders and how many times the tasks were completed successfully.

- The researcher noted the comments and behaviour of the PWD while they looked at their old pictures and applied colour arrangements.

- The researcher went with the PWD outside their homes for more than 200 meters, analysed and noted their reactions to the stop alarm and returning their way home.

\section{Results and Discussion}

\subsection{Demographics of the PWD}

This section highlights the experiences of the PWD who used the $\mathrm{ABC}$ application for performing their daily activities. The demographic information of the PWD is presented in table 2 . 
Table 2. The Demographics of the Participants

\begin{tabular}{|c|c|c|c|c|c|c|}
\hline Participant & Gender & Age & $\begin{array}{c}\text { Living } \\
\text { Place }\end{array}$ & $\begin{array}{c}\text { MMSE } \\
\text { Score }\end{array}$ & $\begin{array}{c}\text { Cognition } \\
\text { Level }\end{array}$ & Volunteers \\
\hline P01 & Male & 71 & Own Home & $21 / 30$ & Mild & 5 \\
\hline P02 & Male & 69 & Own Home & $20 / 30$ & Mild & 5 \\
\hline P03 & Female & 74 & Own Home & $23 / 30$ & Mild & 5 \\
\hline P04 & Male & 66 & Own Home & $21 / 30$ & Mild & 5 \\
\hline P05 & Male & 74 & Own Home & $22 / 30$ & Mild & 5 \\
\hline P06 & Male & 69 & Own Home & $21 / 30$ & Mild & 5 \\
\hline P07 & Male & 71 & Day Care Center & $23 / 30$ & Mild & 5 \\
\hline P08 & Male & 68 & Day Care Center & $22 / 30$ & Mild & 5 \\
\hline
\end{tabular}

There were seven male and one female PWD participants in the case studies with a mean age of 70.3 years. The living situation of the participants indicated that all of them lived with their families; with two of them spent their daytime at the day-care centre. The MMSE scores for the participants ranged from 20 to 23, which indicate that all PWD have mild dementia. Some of the participants have functional difficulties like mobility, remembering, thinking, interaction with others, audio and visual issues. As per discussions with the families and caregivers, the functional status of all the participants was considered partial dependent on the caregivers or family members for completing daily tasks.

\subsection{Interviews for Assessing Features of the Application}

During semi-structured interviews, the functionalities and usage of the $\mathrm{ABC}$ application were discussed with the PWD. All participants appreciated the daily needs at click' and 'travel tutor' functions as useful and relevant; however, the news/weather updates turned out to be their least preferred functionality.

At the start of this study, some family members and caregivers showed their concerns whether the PWD were able to use the $\mathrm{ABC}$ application functions as some of them had vision, hearing and physical mobility challenges. The families also wondered whether the PWD would quickly learn to use the new application. Another concern was whether the PWD would remember to take a mobile device with them while going out with sufficient charge in the mobile. Interestingly none of these concerns happened as all the PWD learned to use the ABC application easily and took sufficiently charged mobile with them while walking outside their home.

\subsection{Themes Originating from the Interviews}

The opinions of the PWD about the ABC application features are one of the critical outcomes from this study. The thematic mapping analysis resulted in six themes (needs support, social support, travel support, cognitive support, information support and memory support). Additionally, the experiences of the PWD belongs to three spheres: the PWD in the society (public sphere), the PWD in the family (family 
sphere) and the feeling of the PWD (emotion sphere). The combination of spheres and themes originating from thematic mapping analysis is shown in table 3.

Table 3: Spheres and Themes

\begin{tabular}{|l|l|}
\hline Sphere & Themes \\
\hline Public Sphere & $\begin{array}{l}\text { Needs Support } \\
\text { Social Support } \\
\text { Travel Support }\end{array}$ \\
\hline Family Sphere & $\begin{array}{l}\text { Cognitive Support } \\
\text { Information Support }\end{array}$ \\
\hline Emotion Sphere & Memory Support \\
\hline
\end{tabular}

\subsubsection{Public Sphere}

The themes that helped to improve social interaction with others belong to the public sphere. For the current study, the themes related to the fulfilment of daily needs, calling and messaging and travel outside the home, all involved interaction with other people. Therefore, these themes are categorized under the public sphere.

\section{Theme 1: Needs Support}

The PWD highly appreciated this functionality and considered it as useful for fulfilling their daily needs. The participant P03 termed it as "comforting to get your desired things at a single click" as this functionality helped him to get his desired needs on just a single click. The same participant also liked to use the daily needs function as it provided him with the opportunity to get not only his desired goods but also the chance to "meet people" from their neighbourhood. The participant P07 had similar views and termed it as "life-changing" as it helped her in minimizing social isolation. She further added, "When the people within the neighbourhood brought her desired goods, they also stayed at her home for few minutes, and enjoyed tea with her".

Theme 2: Social Support

Although some of the PWD were able to use standard mobile phones for making calls to their family and friends, yet they faced challenges like remembering the names and phone numbers of the intended persons. Therefore, the participant P04 considered the picture based call-dialling function to be "useful". The participant P07 mentioned that the photo-based calling would be useful for him when he was not in a good mood and wanted to talk with loved ones. He further added, "I really enjoy this touch and get connected". The Participant P08 said, "Although this functionality is available in other applications as well, the large and clear photos within ABC application make it easier for me to use it”. Although most 
of the participants appreciated the one-touch calling function, however, they were not that much convinced with the one-touch messaging feature as still, they had to type the messages themselves.

Theme 3: Travel Support

The PWD desire to travel independently, but previous research shows that it is usually hard for them due to the nature of dementia. Forgetting ways, getting lost and falls are a few of the many challenges associated with travelling for them. The travel tutor functionality of this application was intended to facilitate the PWD to travel independently outside their homes and ensured that they come back home safely. All participants liked this functionality and used it with interest. The participant P04 said, "I love the travel function when it asks me to stop and go back home". He further added, "Such function can be your friend even when you walk alone". The participant P06 liked the travel instruction commands given by the application and termed it as being a "travel friend" as well. The participants agreed that this functionality would potentially increase their independence and would help to reduce the need for external support.

\subsubsection{Family Sphere}

The themes for interacting with family life belong to this category. The cognitive and information support was considered to intersect with the family lives of the PWD.

Theme 4: Cognitive Support

The PWD talked about how sometimes they forgot to do activities on time and in the correct sequence, and their family members had to help them in such situations. They showed interest in testing the support of the reminders in this regard. The female participant P03 liked medication reminders as it enabled her to take medicine on time. She said, "I like medication reminders as it not only tells me to take medicine but also tells me about details of the dosage”. The Participants P01 and P04 appreciated meal reminders and termed that "It can help them to maintain good health through proper and timely food". The religiousminded participants termed that "religion becomes an essential part of everyday life, especially at the old age". They liked the "prayers reminders" and stated that it could help them to bring "closer to GOD". One of the participant "thanked" the researcher for putting prayers reminders into the ABC application. Some other activity reminders like, (go for a walk, check blood pressure, etc.) did not appeal to the participants as they prefer their family members to involve in such activities. 
Theme 5: Information Support

Everyone needs to remain informed and up to date about happenings around the world. However, it is a hard task for the PWD due to challenges discussed earlier. The ABC application intended to provide up to date news headlines and weather updates for the PWD. The participants liked the news updates as P05 said he feels "well connected to the world around him". The participants, P03 and P06 mentioned that they prefer to hear news updates from family and friends as compared to gadgets. Although a couple of participants showed interest in the weather updates, however, this functionality was least appreciated during the interviews.

\subsubsection{Emotion Sphere}

The emotion sphere refers to theme belonging to the feelings of the participants. The memory support directly affected the emotions of the participants, therefore, positioned under this sphere.

Theme 6: Memory Support

Due to the continuous decline in cognition, it is usually tricky for the PWD to gather exciting memories from their past. The paint memories functionality, therefore, intends to refresh their memories from the glorious past. Overall, the PWD liked this function by uploading black and white pictures to giving colours to these pictures. The participant P06 termed it as confidence-building and said, "Painting my old pictures motivated me to do those activities again that I was used to doing before". He further added, "I get the feeling that if I put some effort, I can do the activities like gardening, shopping, travel independently at my age as well". The participant P08 labelled this functionality to have "pleasant effect" on his mood and made him happier to see old friends in the pictures.

During interviews, some participants said they would have preferred to see their old friends and some relatives make new pictures with them rather than painting the old images.

\subsection{The Usability of the ABC Application}

The usability has many definitions, and the most famous description for the usability comes from the ISO (The International Organization for Standardization). The ISO 9241-11, states that the usability is "the extent to which a product can be used by specified users to achieve specified goals with effectiveness, efficiency, and satisfaction in a specified context of use" (ISO, 1998). The factors considered for the usability ratings in this study include: easy to use function (simple), increase user productivity (effective), 
according to the needs of users (compatible), work efficiently (efficient) and likeness of users to retain this function for future use (retention).

At the end of each interview, the PWD was asked to rate each functionality of the ABC application. The usability ratings are based on their first-hand experience of the application use. Five points Likert scale was used for usability ratings with given choices of 1 for strongly disagree, 2 for disagree, 3 for neutral, 4 for agree and 5 for strongly agree. These ratings are summarized in table 4 .

Table 4.The Usability Ratings for the ABC Application

\begin{tabular}{|c|c|c|c|c|c|c|c|c|c|c|c|}
\hline \multirow[t]{2}{*}{ Functionality } & \multirow[t]{2}{*}{ Rating Scale } & \multicolumn{8}{|c|}{ Participant } & \multirow{2}{*}{$\begin{array}{l}\text { Scale } \\
\text { Score }\end{array}$} & \multirow{2}{*}{$\begin{array}{c}\text { Functionality } \\
\text { Score }\end{array}$} \\
\hline & & P01 & P02 & $\mathrm{P} 03$ & P04 & P05 & P06 & P07 & P08 & & \\
\hline \multirow{5}{*}{ Daily Needs } & Simple & 4 & 5 & 4 & 5 & 5 & 5 & 5 & 5 & 38 & \multirow{5}{*}{191} \\
\hline & Effective & 5 & 5 & 5 & 4 & 5 & 5 & 5 & 5 & 39 & \\
\hline & Compatible & 5 & 4 & 5 & 5 & 4 & 5 & 4 & 4 & 36 & \\
\hline & Efficient & 5 & 5 & 4 & 5 & 5 & 5 & 4 & 5 & 38 & \\
\hline & Retention & 5 & 5 & 5 & 5 & 5 & 5 & 5 & 5 & 40 & \\
\hline \multirow{5}{*}{ Calls/Messages } & Simple & 3 & 5 & 5 & 4 & 5 & 5 & 4 & 5 & 36 & \multirow{5}{*}{181} \\
\hline & Effective & 5 & 4 & 5 & 4 & 5 & 5 & 4 & 5 & 37 & \\
\hline & Compatible & 4 & 5 & 5 & 4 & 4 & 4 & 3 & 5 & 34 & \\
\hline & Efficient & 5 & 5 & 5 & 4 & 5 & 5 & 4 & 4 & 37 & \\
\hline & Retention & 5 & 4 & 5 & 5 & 4 & 5 & 5 & 4 & 37 & \\
\hline \multirow{5}{*}{ Reminders } & Simple & 5 & 5 & 5 & 5 & 5 & 5 & 5 & 4 & 39 & \multirow{5}{*}{186} \\
\hline & Effective & 4 & 5 & 5 & 4 & 5 & 5 & 4 & 5 & 37 & \\
\hline & Compatible & 4 & 5 & 4 & 4 & 3 & 5 & 5 & 5 & 35 & \\
\hline & Efficient & 5 & 4 & 5 & 5 & 5 & 4 & 4 & 5 & 37 & \\
\hline & Retention & 5 & 5 & 5 & 5 & 5 & 5 & 4 & 4 & 38 & \\
\hline \multirow{5}{*}{ Paint Memories } & Simple & 4 & 5 & 5 & 4 & 5 & 5 & 5 & 4 & 38 & \multirow{5}{*}{184} \\
\hline & Effective & 5 & 4 & 5 & 5 & 4 & 4 & 5 & 4 & 36 & \\
\hline & Compatible & 5 & 4 & 5 & 4 & 5 & 3 & 5 & 5 & 36 & \\
\hline & Efficient & 5 & 5 & 4 & 5 & 4 & 5 & 5 & 5 & 38 & \\
\hline & Retention & 4 & 5 & 5 & 4 & 5 & 5 & 5 & 4 & 37 & \\
\hline \multirow{5}{*}{ News/Weather } & Simple & 4 & 5 & 4 & 3 & 4 & 5 & 4 & 4 & 33 & \multirow{5}{*}{173} \\
\hline & Effective & 4 & 5 & 3 & 4 & 5 & 5 & 4 & 5 & 35 & \\
\hline & Compatible & 5 & 4 & 5 & 4 & 4 & 4 & 4 & 5 & 35 & \\
\hline & Efficient & 5 & 5 & 4 & 4 & 4 & 4 & 5 & 4 & 35 & \\
\hline & Retention & 4 & 5 & 4 & 4 & 5 & 5 & 4 & 4 & 35 & \\
\hline \multirow{5}{*}{ Travel Tutor } & Simple & 4 & 5 & 5 & 5 & 5 & 4 & 5 & 5 & 38 & \multirow{5}{*}{190} \\
\hline & Effective & 5 & 5 & 4 & 4 & 4 & 4 & 5 & 5 & 36 & \\
\hline & Compatible & 5 & 4 & 5 & 5 & 5 & 5 & 4 & 5 & 38 & \\
\hline & Efficient & 5 & 5 & 5 & 4 & 5 & 4 & 5 & 5 & 38 & \\
\hline & Retention & 5 & 5 & 5 & 5 & 5 & 5 & 5 & 5 & 40 & \\
\hline
\end{tabular}

The daily needs functionality emerged as the top-rated function by all the participants by securing 191 rating points. The travel tutor got a second high rating by securing 190 rating points. The remaining functionalities scored as; reminders secured 186 rating points, paint your memories got 184 rating points, calls and messages secured 181 rating points and weather and news updates obtained 173 rating points. Overall, most functions got positive feedback. The usability ratings suggest that ABC application is consistent with the usability definition of ISO (ISO, 1998). The daily needs and the travel tutor scored $100 \%$ for retention, which indicates that the PWD wanted to keep on using this application mostly due to these two functionalities. However, as each case study lasted only for a couple of days, and only eight 
PWD participated, we cannot generalize these results. More user trials will be useful in results generalization.

\subsection{Discussion}

This paper describes the development of an application, participation and experiences of the PWD related to this application. Overall, this study belongs to the Erasmus Mundus Fusion Project aimed at supporting the PWD with assistive technologies. The PWD participated in this research project at each stage from requirements elicitation to the development and testing. The project started with an investigation of general assistive technologies used for the PWD reported in (Asghar, Cang, \& Yu, 2015). State of the art in assistive software applications from academic literature and commercially available assistive applications reported in (Asghar et al., 2016). The research continued to explore potential research gaps in this field through the help of bibliometric analysis published in (Asghar et al., 2017a). Based on all findings and identified research gaps through these studies, the research team adapted the semi-structured interviews and questionnaire tools for data collection from the targeted population.

Some previous studies have tried to include assistive functionalities for the PWD in their research. For example, the GPS function was embedded in a smart walker for helping physical mobility of the PWD by (Martins, Santos, Frizera-Neto, \& Ceres, 2012; McCabe \& Innes, 2013). However, it was difficult to use due to its size and weight. The $\mathrm{ABC}$ application overcame this challenge through the travel tutor feature, and this application is installable on a lightweight and small size smartphone. A couple of Mobile multimedia's were developed for communication by (Boman et al., 2014; Donnelly et al., 2010a). However, both these were mock-ups to test the usability of this concept. The ABC application has gone a step forward by implementing the communication feature in the real application. A prompt technology for some simple reminders was proposed by (Seelye, Schmitter-Edgecombe, Das, \& Cook, 2012). Similarly, an electronic memory aid for daily activity management was developed by (Imbeault et al., 2014). These prompt technologies proved useful; however, these support reminders only but do not include details about those reminders. The ABC application not only provides reminders like medication but also tells about the details of the dosage to be taken at specified times. Additionally, this is the first application to support religious activities reminders, which is highly appreciated by the participants.

The daily needs at a click function have not been tried before. This function is a vital contribution to this study. The case studies results show that participants were impressed by this function as it can improve their independence. 
The researchers also added the news and weather updates function. However, it emerged as the least used function in the case studies. The researchers talked about this with the participants, discovered that this function could be improved by showing positive news updates, and avoiding negative updates. This feature can be achieved by using a self-described dictionary (with only positive words) at the backend of this application.

It is concluded that overall, the $\mathrm{ABC}$ application features have a positive impact on the PWD. However, there is a need to improve some of the features, including weather/news updates and reminders. The HCI community can take this study as a stepping-stone and researchers can further explore software features introduced in this study in different settings.

\subsubsection{Study Contributions}

In summary, the case studies helped achieve the first objective, and thematic mapping analysis helped accomplish the second objective. Also, this study has multiple contributions in the form of advantages as compared with existing applications for the PWD. It provides many modules, tailored to the needs of the PWD. The solution offered through this study is low cost, and it supports multiple features. The application itself is straightforward to install on the smart devices, and the user does not have to carry traditional heavy gadgets.

Considering the interaction of humans with the technology the solution presented in this study encourages participation of people within the neighbourhood to support the PWD. Additionally, the idea of assistive communities promotes the combination of technology support and personal care.

The unique point about this study is that to the best of authors' knowledge; this is the first study of daily needs at a click and reminders related to religious activities. Considering the broader perspective, this is the first study in Pakistan and South Asia to evaluate a software solution focused on the need of the PWD.

\subsubsection{Lessons Learned}

Overall, this study received appreciation from the participants, especially from the PWD; however, some areas need further improvements. There are many lessons learned from this study as well. The participants had reservations on using one touch-messaging feature, as they still have to type the message by themselves. Researchers can experiment with this issue by introducing voice commands messaging (using speech recognition). While the participants appreciated medication, food and religious reminders, 
they did not like reminders such as, go for a walk; check blood pressure, etc., as they wanted their family to involve in such activities. Therefore, too much use of reminders is not encouraged. The participants did enjoy memory painting feature; however, they preferred to see their loved ones in real, rather than through old pictures. Therefore, we recommend using technology with a combination of proper human care.

The least appreciated feature is weather updates. It could be because usually, the weather in Pakistan do not change suddenly as in western countries like the UK. However, this feature may be useful to test in countries with sudden weather changes. Currently, the travel tutor does not send the location of the PWD to family or caregivers. This feature can be integrated into the application for better safety of the users.

\section{Study Limitations}

This study has a few limitations as well. The sample size is rather small and is based on convenience samples. The ABC application is tested with the PWD having mild dementia only; the moderate and severe dementia population is not checked. We trained the PWD before actual use; however, in the real world, it might not be possible that all users have the opportunity to get training before using such applications. The researcher stayed with the PWD during case studies, which may generate biases in the results. Additionally, all requirements of the PWD cannot be fulfilled by a single piece of technology. Therefore, more efforts are needed on the part of researchers to come up with user-friendly assistive technologies. The future studies can also include caregivers and family members, along with PWD in the case studies.

\section{Conclusion and Future Work}

This study highlighted the features and usability of an assistive software application developed for the PWD. Eight case studies were performed at five different cities of Pakistan involving 8 PWD and 40 volunteers. The PWD used the application for two days and were interviewed at the end of the case studies.

Generally, the PWD enjoyed using the ABC application, especially liked the daily needs at click and travel tutor functionalities. The PWD did show some concerns about using too many reminders and wanted their families to be part of some tasks rather than being dependent on technology. Yet, they showed an interest in the $\mathrm{ABC}$ application and were keen to continue using this application. They specifically appreciated the increased socialization opportunities by using the $\mathrm{ABC}$ application. 
We believe that by mitigating the limitations identified through this study, and further work on such applications can support the PWD in gaining confidence and improved independence. The realization of user-friendly assistive brotherhood communities has the potential to prolong the stay of the PWD at their own homes, which in return can save a lot of resources and money for the families and the Governments. Future work should remove negative news updates and sending the location of the PWD to family members, once the user goes away from a specified safe distance. The application should be tested with a larger sample and for more extended periods. Similar case studies should be carried out in Western countries as well to promote cohesion of street-level communities.

\section{Acknowledgements}

The authors acknowledge the support of the people with dementia, their families, the volunteers, hospitals and medical professionals. This work was supported by the Erasmus Mundus Fusion Project (grant numbers 545831-EM-1-2013-1-IT-ERAMUNDUSEMA21), EU Horizon2020 MARIE SKŁODOWSKA-CURIE RISE, Characterisation of a green microenvironment and to study its impact upon health and well-being in the elderly as a way forward for health tourism project (H2020-MSCARISE-2016-734684, and in part by the Royal Society International Exchanges Scheme (Adaptive Learning Control of a Cardiovascular Robot Using Expert Surgeon Techniques) Project under Grant IE151224.

\section{Conflict of Interest}

The authors declare that there is no conflict of interest

\section{References}

Ahmad, A., Owais, K., Siddiqui, M., Mamun, K., Rao, F., \& Yousufzai, A. W. (2013). Dementia in Pakistan: National Guidelines for Clinicians. PJNS, 8(3), 17-27.

Ali, S., \& Bokharey, I. Z. (2015). Maladaptive cognitions and physical health of the caregivers of dementia: An interpretative phenomenological analysis. International journal of qualitative studies on health and well-being, 10.

Aloulou, H., Mokhtari, M., Tiberghien, T., Biswas, J., Phua, C., Lin, J. H. K., \& Yap, P. (2013). Deployment of assistive living technology in a nursing home environment: methods and lessons learned. BMC medical informatics and decision making, 13(1), 42.

Asghar, I., Cang, S., \& Yu, H. (2015). A systematic mapping study on assitive technologies for people with dementia. Paper presented at the Software, Knowledge, Information Management and Applications (SKIMA), 2015 9th International Conference on. 
Asghar, I., Cang, S., \& Yu, H. (2016). Software based assistive technologies for people with dementia: Current achievements and future trends. Paper presented at the Software, Knowledge, Information Management \& Applications (SKIMA), 2016 10th International Conference on.

Asghar, I., Cang, S., \& Yu, H. (2017a). Assistive technology for people with dementia: an overview and bibliometric study. Health Information \& Libraries Journal.

Asghar, I., Cang, S., \& Yu, H. (2017b). Usability Evaluation of Assistive Technologies through Qualitative Research Focusing on People with Mild Dementia. Computers in Human Behavior.

Asghar, I., Cang, S., \& Yu, H. (2018a). Impact evaluation of assistive technology support for the people with dementia. Assistive Technology, 1-13.

Asghar, I., Cang, S., \& Yu, H. (2018b). Usability evaluation of assistive technologies through qualitative research focusing on people with mild dementia. Computers in Human Behavior, 79, 192-201.

$\mathrm{Au}, \mathrm{A}$., Lai, S., \& Ng, E. (2015). Introduction: Mental Health of Older Adults in Asia. Clinical Gerontologist, 38(3), 187189.

Beuscher, L., \& Grando, V. T. (2009). Challenges in conducting qualitative research with persons with dementia. Research in Gerontological nursing, 2(1), 6 .

Boman, I.-L., Lundberg, S., Starkhammar, S., \& Nygård, L. (2014). Exploring the usability of a videophone mock-up for persons with dementia and their significant others. BMC geriatrics, 14(1), 49.

Braun, V., \& Clarke, V. (2006). Using thematic analysis in psychology. Qualitative research in psychology, 3(2), 77-101.

Carrillo, M. C., Dishman, E., \& Plowman, T. (2009). Everyday technologies for Alzheimer's disease care: Research findings, directions, and challenges. Alzheimer's \& Dementia, 5(6), 479-488.

Chamie, J. (2004). World population prospects: The 2002 revision. New York United Nations Department of Economic and Social Affairs Analytical Report III.

Chaurasia, P., McClean, S. I., Nugent, C. D., Cleland, I., Zhang, S., Donnelly, M. P., . . Norton, M. C. (2016). Modelling assistive technology adoption for people with dementia. Journal of biomedical informatics, 63, 235-248.

Cire, B. (2015, 27-October-2015). Health care costs for dementia found greater than for any other disease. Retrieved from https://www.nia.nih.gov/newsroom/2015/10/health-care-costs-dementia-found-greater-any-other-disease

Conway, N., Campbell, I., Forbes, P., Cunningham, S., \& Wake, D. (2016). mHealth applications for diabetes: User preference and implications for app development. Health informatics journal, 22(4), 1111-1120.

Dey, A. K., \& Abowd, G. D. (2000). Cybreminder: A context-aware system for supporting reminders. Paper presented at the Handheld and Ubiquitous Computing.

Donnelly, Nugent, C., McClean, S., Scotney, B., Mason, S., Passmore, P., \& Craig, D. (2010a). A mobile multimedia technology to aid those with Alzheimer's disease. IEEE multimedia, 2(17), 42-51.

Donnelly, Nugent, C. D., McClean, S. I., Scotney, B. W., Mason, S., Passmore, P. J., \& Craig, D. (2010b). A mobile multimedia technology to aid those with Alzheimer's disease. IEEE multimedia, 17(2), 42-51.

Drever, E. (1995). Using Semi-Structured Interviews in Small-Scale Research. A Teacher's Guide: ERIC.

Engström, M., Lindqvist, R., Ljunggren, B., \& Carlsson, M. (2006). Relatives' opinions of IT support, perceptions of irritations and life satisfaction in dementia care. Journal of telemedicine and telecare, 12(5), 246-250.

Engström, M., Lindqvist, R., Ljunggren, B., \& Carlsson, M. (2009). Staff members' perceptions of a ICT support package in dementia care during the process of implementation. Journal of nursing management, 17(7), 781-789.

Engström, M., Ljunggren, B., Lindqvist, R., \& Carlsson, M. (2005). Staff perceptions of job satisfaction and life situation before and 6 and 12 months after increased information technology support in dementia care. Journal of telemedicine and telecare, 11(6), 304-309.

Fardoun, H. M., Mashat, A. A., \& Ramirez Castillo, J. (2015). Recognition of familiar people with a mobile cloud architecture for Alzheimer patients. Disability and Rehabilitation, 1-5.

Faucounau, V., Riguet, M., Orvoen, G., Lacombe, A., Rialle, V., Extra, J., \& Rigaud, A.-S. (2009). Electronic tracking system and wandering in Alzheimer's disease: a case study. Annals of physical and rehabilitation medicine, 52(7), 579-587.

Fleming, R., \& Sum, S. (2014). Empirical studies on the effectiveness of assistive technology in the care of people with dementia: a systematic review. Journal of Assistive Technologies, 8(1), 14-34.

Hoey, J., Poupart, P., von Bertoldi, A., Craig, T., Boutilier, C., \& Mihailidis, A. (2010). Automated handwashing assistance for persons with dementia using video and a partially observable markov decision process. Computer Vision and Image Understanding, 114(5), 503-519.

Imbeault, H., Bier, N., Pigot, H., Gagnon, L., Marcotte, N., Fulop, T., \& Giroux, S. (2014). Electronic organiser and Alzheimer's disease: Fact or fiction? Neuropsychological rehabilitation, 24(1), 71-100.

International, A. (2017). Dementia statistics. Retrieved from https://www.alz.co.uk/research/statistics 
Ireland, A. (2015). Media Guidelines Interviewing/Meeting People with Dementia. Retrieved from https://www.alzheimer.ie/About-Us/News-and-Media/Media-Guidelines-Interviewing-Meeting-People-with.aspx

ISO. (1998). 9241-11. Ergonomic requirements for office work with visual display terminals (VDTs). The international organization for standardization, 45(9).

Jones, K. (2004). Enabling technologies for people with dementia. Report of the assessment study in England.

Labelle, K.-L., \& Mihailidis, A. (2006). The use of automated prompting to facilitate handwashing in persons with dementia. American Journal of Occupational Therapy, 60(4), 442-450.

Mann, J. A., MacDonald, B. A., Kuo, I.-H., Li, X., \& Broadbent, E. (2015). People respond better to robots than computer tablets delivering healthcare instructions. Computers in Human Behavior, 43, 112-117.

Martins, M. M., Santos, C. P., Frizera-Neto, A., \& Ceres, R. (2012). Assistive mobility devices focusing on Smart Walkers: Classification and review. Robotics and Autonomous Systems, 60(4), 548-562.

McCabe, L., \& Innes, A. (2013). Supporting safe walking for people with dementia: User participation in the development of new technology. Gerontechnology, 12(1), 4-15.

Mihailidis, A., Boger, J. N., Craig, T., \& Hoey, J. (2008). The COACH prompting system to assist older adults with dementia through handwashing: An efficacy study. BMC Geriatr, $8(1), 1$.

Mordoch, E., Osterreicher, A., Guse, L., Roger, K., \& Thompson, G. (2013). Use of social commitment robots in the care of elderly people with dementia: A literature review. Maturitas, 74(1), 14-20.

Pratchett, T. (2015). A global assessment of dementia, now and in the future. The Lancet Neurology, $14,691$.

Prince, M., Bryce, R., Albanese, E., Wimo, A., Ribeiro, W., \& Ferri, C. P. (2013). The global prevalence of dementia: a systematic review and metaanalysis. Alzheimer's \& Dementia, 9(1), 63-75. e62.

Rasul, G. (2014). Food, water, and energy security in South Asia: A nexus perspective from the Hindu Kush Himalayan region ${ }_{3}$. Environmental Science \& Policy, 39, 35-48.

Sawyer, P., Sutcliffe, A., Rayson, P., \& Bull, C. (2015). Dementia and social sustainability: challenges for software engineering. Paper presented at the Software Engineering (ICSE), 2015 IEEE/ACM 37th IEEE International Conference on.

Schikhof, Y., Mulder, I., \& Choenni, S. (2010). Who will watch (over) me? Humane monitoring in dementia care. International Journal of Human-Computer Studies, 68(6), 410-422.

Seelye, A. M., Schmitter-Edgecombe, M., Das, B., \& Cook, D. J. (2012). Application of cognitive rehabilitation theory to the development of smart prompting technologies. Biomedical Engineering, IEEE Reviews in, 5, 29-44.

Span, M., Hettinga, M., Vernooij-Dassen, M., Eefsting, J., \& Smits, C. (2013). Involving people with dementia in the development of supportive IT applications: A systematic review. Ageing research reviews, 12(2), 535-551.

Tchalla, A. E., Lachal, F., Cardinaud, N., Saulnier, I., Bhalla, D., Roquejoffre, A., . . Dantoine, T. (2012). Efficacy of simple home-based technologies combined with a monitoring assistive center in decreasing falls in a frail elderly population (results of the Esoppe study). Archives of gerontology and geriatrics, 55(3), 683-689.

Van Hoof, J., Kort, H., Duijnstee, M., Rutten, P., \& Hensen, J. (2010). The indoor environment and the integrated design of homes for older people with dementia. Building and Environment, 45(5), 1244-1261.

Wancata, J., Musalek, M., Alexandrowicz, R., \& Krautgartner, M. (2003). Number of dementia sufferers in Europe between the years 2000 and 2050. European Psychiatry, 18(6), 306-313.

Wu, Y.-H., Wrobel, J., Cristancho-Lacroix, V., Kamali, L., Chetouani, M., Duhaut, D., . . Ghrissi, M. (2013). Designing an assistive robot for older adults: The ROBADOM project. IRBM, 34(2), 119-123.

Zaidi, A., Willis, R., Farina, N., Balouch, S., Jafri, H., Ahmed, I., . . Jaffri, R. (2019). Understanding, beliefs and treatment of dementia in Pakistan. 


\section{Author Profiles:}

Dr Ikram Asghar is working as a Research and Development Associate at the University of South Wales, UK. He holds PhD in Computing form the Bournemouth University, UK. His research interests include human-computer interaction, assistive technologies for people with disabilities and emerging technologies.

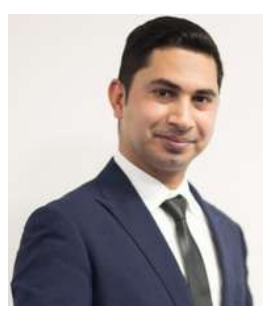

Dr Shuang Cang is an associate Professor at Department of Computing and Technology, School of Science and Technology, Nottingham Trent University, UK. She has both industry and academic experience. Previously she worked for a leading UK software company, Bournemouth University, Exeter University and the University of Wales. Her expertise includes artificial intelligence, data science and quantitative analysis

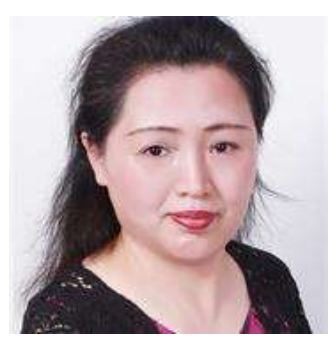

Prof. Hongnian Yu is a Professor at the School of Engineering and The Built Environment, Edinburgh Napier University,

UK. He has held academic positions at the Bournemouth University, Universities of Sussex, Liverpool John Moor, Exeter, Bradford and Staffordshire. He has extensive research experience in mobile computing, computer networks, control of robots and neural networks and computing. He has published over 200 journal and conference research papers.

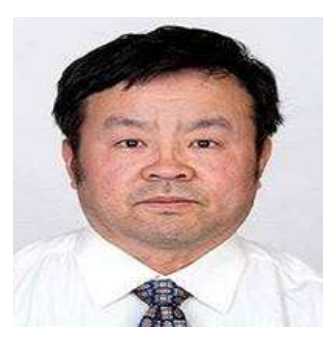

